\title{
Pd(0)-Catalyzed Directed syn-1,2-Carboboration and -Silylation: Alkene Scope, Applications in Dearomatization, and Stereocontrol via a Chiral Auxiliary
}

\author{
Zhen Liu, ${ }^{\dagger}$ Jiahao Chen, ${ }^{\dagger}$ Xiaohan $\mathrm{Li}^{+}{ }^{+}$Yang Gao, ${ }^{\dagger}$ John R. Coombs, ${ }^{\ddagger}$ Matthew J. Goldfogel, ${ }^{\ddagger}$ Keary M. Engle ${ }^{*,+}$ \\ ${ }^{+}$Department of Chemistry, The Scripps Research Institute, 10550 North Torrey Pines Road, La Jolla, California 92037, United States \\ ${ }^{\ddagger}$ Chemical Development, Bristol-Myers Squibb, One Squibb Drive, New Brunswick, New Jersey 08903, United States
}

Supporting Information Placeholder

\begin{abstract}
We report the development of palladium(0)-catalyzed syn-selective 1,2-carboboration and -silylation reactions of alkenes containing cleavable directing groups. With $\mathrm{B}_{2} \mathrm{pin}_{2}$ or $\mathrm{PhMe}_{2} \mathrm{Si}-\mathrm{Bpin}$ as nucleophiles and aryl/alkenyl triflates as electrophiles, a broad range of mono-, di-, tri- and tetrasubstituted alkenes are compatible in these transformations. We further describe a directed dearomative 1,2-carboboration of electron-rich heteroarenes by employing this approach. Through use of a removable chiral directing group, we demonstrate the viability of achieving stereoinduction in Heck-type alkene 1,2-difunctionalization. This work introduces new avenues to access highly functionalized boronates and silanes with precise regioand stereocontrol.
\end{abstract}

Metal-catalyzed 1,2-carboboration of alkenes is a powerful means of simultaneously forming a $\mathrm{C}\left(\mathrm{sp}^{3}\right)-\mathrm{C}$ and a $\mathrm{C}\left(\mathrm{sp}^{3}\right)-\mathrm{B}$ bond in a single step with multiple levels of selectivity control. ${ }^{1}$ Indeed, successful examples of catalytic 1,2-carboboration have been developed with copper, ${ }^{2}$ palladium, ${ }^{3}$ nickel, ${ }^{4}$ and dual catalyst systems ${ }^{5}$. Of the various coupling partners that can be engaged in 1,2-carboboration, organohalides and pseudohalides are particularly important, given the structural diversity and widespread availability of these electrophiles (Scheme 1A). In this area, classical limitations have included the scope of compatible alkenes and associated issues with regiocontrol; indeed, the vast majority of successful examples involve activated alkenes, such as styrenes ${ }^{2 \mathrm{a}, \mathrm{f}, 3 \mathrm{a}, 4 \mathrm{c}, \mathrm{d}, \mathrm{s}}$ or norbornenes (Scheme 1B). ${ }^{2 \mathrm{~d}, 3 \mathrm{~b}}$ Previously, Xiao and $\mathrm{Fu}$ developed a $\mathrm{Cu}$-catalyzed regiodivergent 1,2-alkylboration of non-conjugated terminal alkenes containing a proximal heteroatom. ${ }^{2 c}$ Recently, Brown has developed an elegant series of nickel-catalyzed 1,2-arylboration methods capable of functionalizing mono-, di- and trisubstituted non-conjugated alkenes ${ }^{4 a, b}$ without formation of competitive chain-walking products. ${ }^{6,7}$ These reactions are believed to proceed via a $\mathrm{Ni}^{\mathrm{I}}-\mathrm{B}$ pin intermediate, which generally delivers the Bpin group to the less substituted carbon atom. With trisubstituted alkenes, the reactions are highly regioselective, whereas with non-symmetric 1,2-disubstituted alkenes and terminal alkenes, regiomeric ratios (r.r.) are variable and controlled by a combination of steric and electronic factors.

To complement these approaches, we reasoned that a substrate-directed strategy involving palladium catalysis could enhance reactivity with hindered substrates (e.g., tetrasubstituted alkenes ${ }^{8}$ ) and provide a means of controlling regioselectivity in a manner that is independent of the alkene substitution pattern. Previously, our lab ${ }^{9}$ and others ${ }^{10}$ have developed a toolkit of hydro- and difunctionalization reactions of alkenyl carbonyl compounds bearing the 8 -aminoquinoline ${ }^{11}$ (AQ) directing group. As part of this effort, we described an anti-selective 1,2-carboboration of alkenyl carbonyl compounds that initiates via Wacker-type carbopalladation (Scheme 1C). ${ }^{3 c-e}$ Though useful in its own right, this method is limited in terms of the carbogenic groups that can be introduced (indole-type nucleophiles) and the alkene scope (terminal and 1,2-disubstituted alkenes). We hypothesized that these issues could be overcome by developing a catalytic system that instead initiates via Heck-type 1,2-migratory insertion. . $^{9, f, 10 b, e}$ Based on this idea, herein we describe a Heck-type directed 1,2-carboboration that proceeds via a $\mathrm{Pd}(0) / \mathrm{Pd}(\mathrm{II})$ redox manifold (Scheme 1D). In addition to tolerating essentially all possible alkene substitution patterns, the protocol can also be applied in directed dearomative 1,2-carboboration of electron-rich heterocycles. The generality of this directed 1,2-difunctionalization approach via $\mathrm{Pd}(0) / \mathrm{Pd}(\mathrm{II})$ catalysis is demonstrated through the realization of a 1,2-carbosilylation method by using $\mathrm{PhMe}_{2} \mathrm{Si}-\mathrm{Bpin}{ }^{12}$ in place of $\mathrm{B}_{2} \mathrm{Pin}_{2}$. Lastly, stereoinduction by use of a chiral directing group is shown.

Scheme 1. Background and Project Synopsis

A. three-component 1,2-carboboration with organohalide/pseudohalide

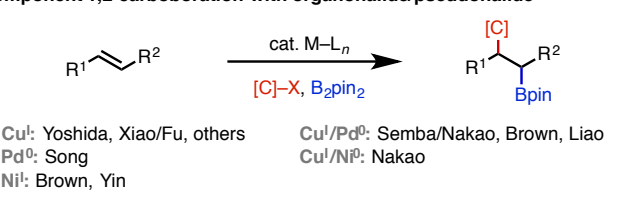

B. survey of substrates that have been employed in intermolecular 1,2-carboboration

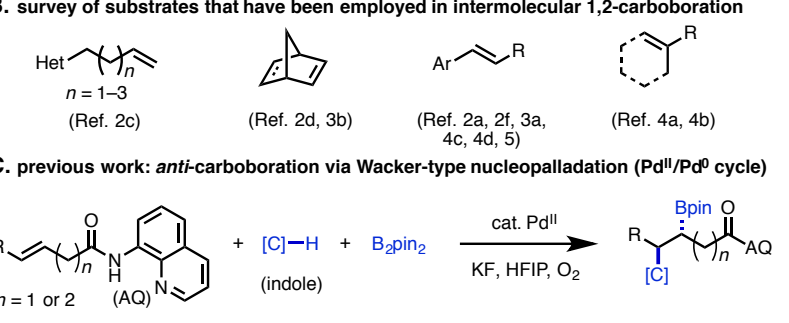

D. this work: syn-carboboration/silylation via Heck-type migratory insertion ( $\mathrm{Pd}^{0} / \mathrm{Pd}^{\prime \prime}$ cycle)

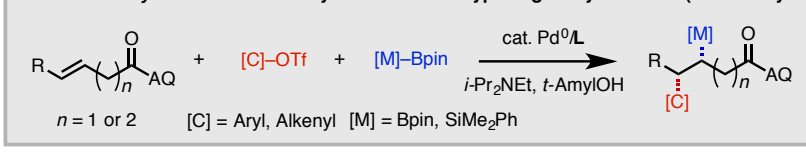

To initiate our study, we first selected 8-aminoquinoline (AQ)-masked 3-butenoic acid (1a) and (E)-3-hexenoic acid (1c) as our pilot alkene substrates, phenyl triflate $(\mathbf{2 a})$ as the electrophile, and $\mathrm{B}_{2} \operatorname{pin}_{2}(\mathbf{3 a})$ as the boron-based nucleophile. We elected to use a catalyst system consisting of $\mathrm{Pd}_{2} \mathrm{dba}_{3}$ and a phosphine ligand. ${ }^{10 \mathrm{~b}} \mathrm{We}$ hypothesized that the phosphine ligand would coordinate to $\operatorname{Pd}(0)$ and promote oxidative addition to the aryl triflate. After extensive screening of different ligands, bases, and reaction solvents (see SI for details), we identified an optimal combination: $i$ - $\mathrm{Pr}_{2} \mathrm{NEt}$ as base and $t$-AmylOH as solvent with a Buchwald-type ligand, ${ }^{13}$ such as RuPhos, XPhos, or Cy-JohnPhos (L). Under these conditions syn-1,2-arylborylated products $\mathbf{4 a}$ and $\mathbf{4 c}$ could be isolated in nearly quantitative yield without observable formation of regio- and stereoisomers based on ${ }^{1} \mathrm{H}$ NMR. 
We then tested the alkene scope of this $\operatorname{Pd}(0)$-catalyzed 1,2-arylboration (Table 1). Pleasingly, we found that a remarkably broad collection of alkenes were reactive. For $\beta, \gamma$-unsaturated carbonyl compounds, which react via five-membered palladacycles, the reaction was largely insensitive to the alkene substitution pattern. Di-, tri-, and even tetrasubstituted alkenes were all competent, leading to a variety of secondary and tertiary alkyl boronates in excellent yields $(\mathbf{4 a - k})$. These results stand in contrast to our previously developed directed 1,2-difunctionalization reactions involving Wacker-type nucleopalladation, ${ }^{3 c, 9 b, c, e}$ which are highly sensitive to steric hindrance and are incompatible with tri- and tetrasubstituted alkenes. Substrate 1h, which is derived from Vince lactam, ${ }^{14}$ underwent arylboration smoothly to give product $\mathbf{4 h}$, which bears four substituents on the same face of the cyclopentane ring. Furthermore, from tetrasubstituted alkene $1 \mathbf{k}$, the resulting product contains two contiguous quaternary centers, a motif that is inaccessible using existing arylboration methods.

The reaction also works reasonably well for substrates containing one additional methylene spacer between the $\mathrm{C}=\mathrm{C}$ bond and the carbonyl groups (41-p), which react via six-membered palladacycles. However, with these substrates, the reaction is more sensitive to steric hindrance. With 1,2-disubstituted alkene $1 \mathbf{m}$, the product $(\mathbf{4 m})$ was obtained in $85 \%$ yield, which is slightly diminished compared to analogous earlier examples $(\mathbf{4 b}-\mathbf{4 d})$. With trisubstituted alkene 1r, no reaction was observed. We attribute this pattern of attenuated reactivity to less favorable kinetics and thermodynamics for 1,2-migratory insertion to form a six-membered palladacycle versus a five-membered palladacycle. Substrates with even more distal alkenes, including terminal alkene 1s, were unreactive under the standard conditions. Interestingly, an alkenyl amine substrate containing a picolinamide (PA) directing group also underwent 1,2-arylboration in moderate yield (4q). Importantly, across all of these examples, the phenyl group was reliably delivered to position distal to the AQ group, and the Bpin group moiety was installed proximal to the AQ group, irrespective of alkene substitution pattern, illustrating a unique aspect of this directed 1,2-carboboration compared to other approaches. ${ }^{1-5}$

Table 1. Alkene Scope of 1,2-Arylboration ${ }^{a}$

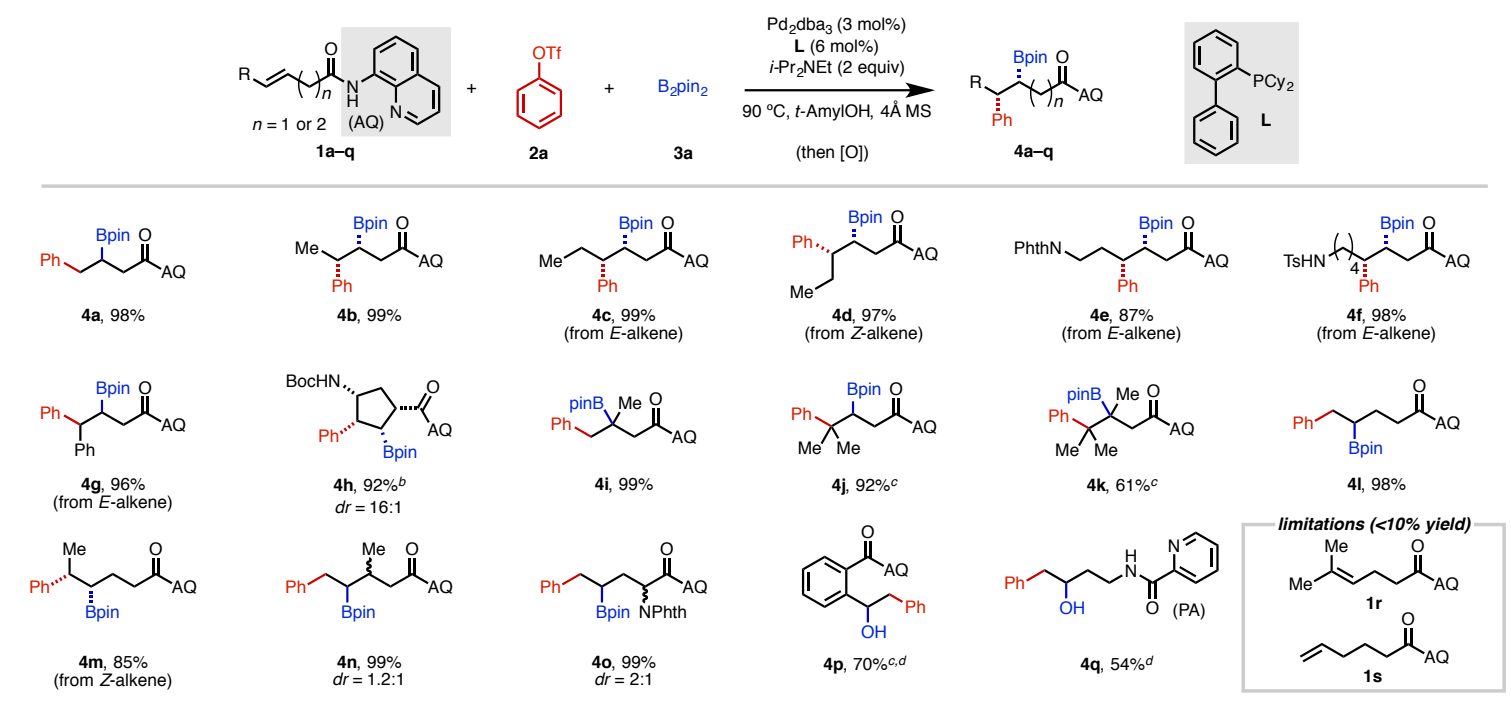

${ }^{a}$ Reaction conditions: $\mathbf{1 a}-\mathbf{q}(0.05$ or $0.1 \mathrm{mmol}), \mathbf{2 a}$ (1.5 equiv), 3a (2 equiv), $\mathrm{Pd}_{2} \mathrm{dba}_{3}$ ( $\left.3 \mathrm{~mol} \%\right), \mathbf{L}(6 \mathrm{~mol} \%), i-\mathrm{Pr}_{2} \mathrm{NEt}(2 \mathrm{equiv}), 4 \AA ̊ \mathrm{MS}$ ( $\left.15-30 \mathrm{mg}\right)$, $90{ }^{\circ} \mathrm{C}, \mathrm{N}_{2}, 38-44 \mathrm{~h}$. Percentages refer to isolated yields. Unless otherwise noted, diastereomeric ratio (dr) was found to be $>30: 1$ in all cases. ${ }^{b} \mathbf{2 a}(3$

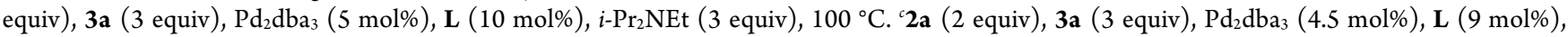
$i-\mathrm{Pr}_{2} \mathrm{NEt}$ ( 3 equiv). ${ }^{d}$ The final product was oxidized to the corresponding alcohol with $\mathrm{NaBO}_{3} \cdot 4 \mathrm{H}_{2} \mathrm{O}$ ( 5 equiv) for the ease of isolation.

Table 2. Electrophile Scope ${ }^{a}$

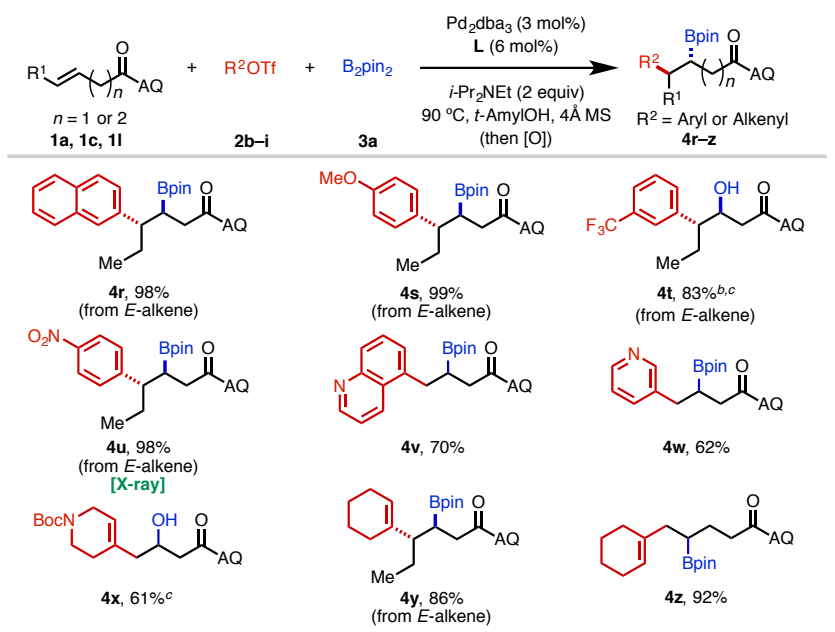

${ }^{a}$ Unless otherwise specified, reaction conditions were as in Table $1 . \mathrm{dr}$ values were found to be $>30: 1$ in all cases. ${ }^{b} \mathbf{2 d}$ ( 2 equiv), $3 \mathbf{3 a}$ ( 3 equiv). 'The final product was oxidized to the corresponding alcohol with $\mathrm{NaBO}_{3} \cdot 4 \mathrm{H}_{2} \mathrm{O}$ (5 equiv) for the ease of isolation.

Next, we investigated the compatibility of carbon electrophiles in this transformation (Table 2). An array of aryl triflates containing substituents with different electronic properties on the para or meta positions reacted smoothly under the optimal conditions, delivering the corresponding products, $\mathbf{4 r}-\mathbf{4 u}$, in excellent yields. Notably heteroaryl triflates containing a Lewis basic $\mathrm{N}\left(\mathrm{sp}^{2}\right)$ atom $(\mathbf{4 v}$ and $\mathbf{4 w})$, which are incompatible in many Pd-catalyzed alkene functionalizations, are tolerated in this reaction, though slightly lower yields were obtained. Gratifyingly, when we used alkenyl triflates $\mathbf{2 h}$ and $\mathbf{2} \mathbf{i}$ as carbon electrophiles, 1,2-alkenylboration could be achieved. Both 3-butenoic acid and 4-pentenoic acid derivatives underwent alkenylboration in good to excellent yields $(\mathbf{4 x}-\mathbf{4 z})$. 
Scheme 2. Gram-Scale 1,2-Arylboration

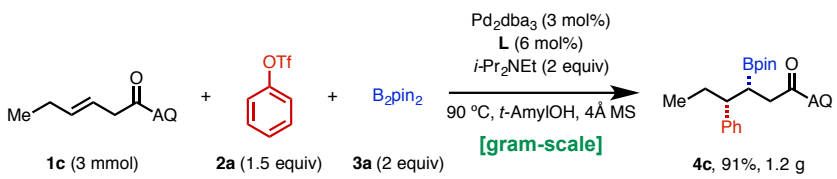

In order to demonstrate the method's operational simplicity and practicality, we scaled up the alkene arylboration reaction using $\mathbf{1 c}$ as a model substrate (Scheme 2). Under standard conditions, boronate $\mathbf{4 c}$ was isolated in $91 \%$ yield $(1.2 \mathrm{~g})$.

Considering the relatively expensive nature of aryl triflates, we also investigated other aryl electrophiles as triflate surrogates. Aryl fluorosulfates, ${ }^{15}$ which can be readily prepared from phenols and sulfurylfluoride $\left(\mathrm{SO}_{2} \mathrm{~F}_{2}\right)$, are a class of inexpensive aryl electrophiles that are used on industrial scale, making them attractive yet underutilized coupling partners in alkene functionalization. To our delight, phenyl fluorosulfate $(\mathbf{2} \mathbf{j})$ was found to be a highly effective electrophile in this 1,2-arylboration reaction, providing nearly quantitative yield of $\mathbf{4 c}$ (Scheme 3 ).

Scheme 3. Arylboration using Phenyl Fluorosulfate as the Electrophile

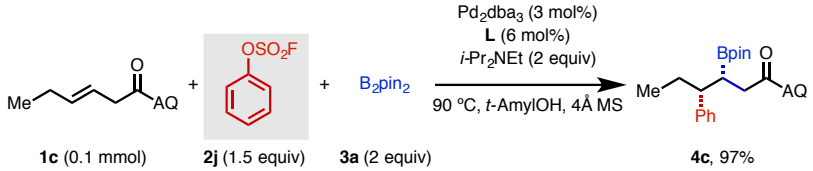

Table 3. Dearomative Aryl/Alkenylboration of Heterocycles ${ }^{a}$

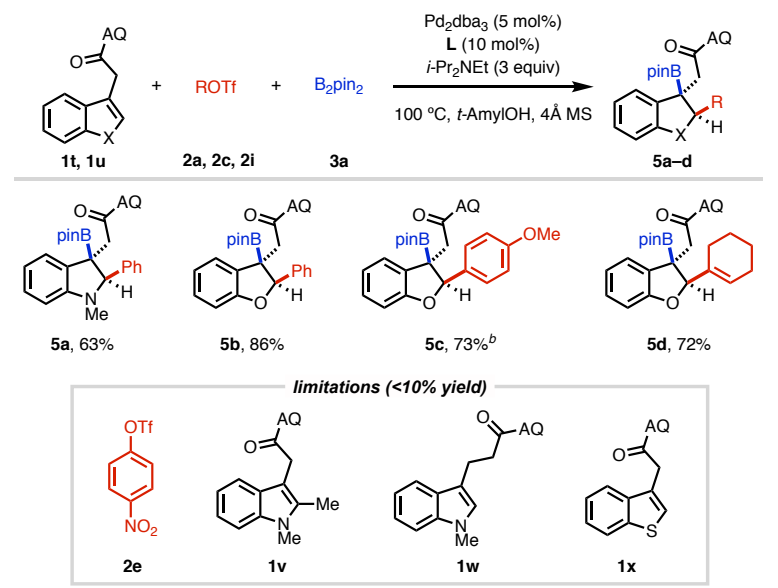

${ }^{a}$ Reaction conditions: $\mathbf{1 r}$ or $\mathbf{1 s}(0.05$ or $0.1 \mathrm{mmol}), \mathbf{2 a}, \mathbf{2 c}$, or $2 \mathbf{i}(3$ equiv), 3a ( 3 equiv), $\mathrm{Pd}_{2} \mathrm{dba}_{3}(5 \mathrm{~mol} \%), \mathbf{L}(10 \mathrm{~mol} \%), i-\mathrm{Pr}_{2} \mathrm{NEt}(3$ equiv), $4 \AA ̊$ MS (20-30 mg), $100{ }^{\circ} \mathrm{C}, \mathrm{N}_{2}, 38-44 \mathrm{~h}$. Percentages refer to isolated yields. The diastereomeric ratio $(\mathrm{dr})$ was found to be $>30: 1$ in all cases. ${ }^{b} \mathbf{1 s}(0.1 \mathrm{mmol}), \mathbf{2 c}$ ( 2 equiv), $\mathrm{Pd}_{2} \mathrm{dba}_{3}(4.5 \mathrm{~mol} \%), \mathbf{L}(9$ $\mathrm{mol} \%)$.

Given the broad scope of this reaction and its insensitivity to alkene substitution patterns, we next questioned whether it was possible to carry out directed dearomative 1,2 -difunctionalization ${ }^{16}$ of heteroarenes (Table 3). Three-component 1,2-carboboration of heteroarenes would represent a powerful way to prepare highly functionalized heterocycles. However, this type of reaction has not been previously reported in the literature to the best of our knowledge. The envisioned transformation is challenging for several reasons, including the potential for competitive two-component Miyaura borylation, the relatively large energy barrier associated with breaking aromaticity, and the possibility of undergoing rearomatization. Taking inspiration from an elegant recent report by Jia, Lautens and coworkers on $\mathrm{Pd}(0)$-catalyzed intramolecular dearomative arylboration of indoles, ${ }^{17}$ we reasoned that the aforementioned issues could be overcome through AQ-directed Heck-type migratory.

Gratifyingly, using this substrate directivity strategy, we were able to effect 1,2-carboboration of indoles and benzofurans in good yields and with excellent diastereoselectivity (5a-5d). Several benzo-fused heterocyclic products containing a tertiary boronate group could thus be prepared in a succinct manner. This dearomative transformation is not without its limitations. Aryl triflates bearing strong electron-withdrawing groups are incompatible in this reaction. With indole substrates bearing a 2-substituent (1v) or one extra methylene spacer (1w), similarly no reaction was observed. A benzothiophene derivative $\mathbf{1} \mathbf{x}$ was also unreactive in this transformation.

To demonstrate the versatility of directed Heck-type 1,2-difunctionalization chemistry, we next sought to develop a method for three-component alkene 1,2-carbosilyation, a transformation that would be synthetically enabling yet remains underdeveloped in the literature. ${ }^{18,19}$ To this end, we tested Suginome's $\mathrm{PhMe}_{2} \mathrm{Si}-\mathrm{Bpin}$ reagent $^{12}$ (3b) in place of $\mathrm{B}_{2} \operatorname{pin}_{2}$ (3a). Gratifyingly, after brief optimization we identified conditions for alkene 1,2-carbosilylation (Table 4). ${ }^{20}$ Although silyl group transfer to the $\mathrm{Pd}(\mathrm{II})$ center was generally favored over boryl group transfer, small amounts of the 1,2-carboborylated byproduct could nevertheless be detected. This competitive pathway accounts for the slightly lower product yields in this transformation. Representative examples of alkene substrates and electrophiles were examined, and yields were consistently in the moderate to good range (6a-6f). 4-Pentenoic acid derivatives (such as 11), however, were incompatible in this transformation. In this case, only a small amount of arylsilylated product was generated, together with alkene arylboration and hydroarylation byproducts.

Table 4. Scope of Alkene Aryl/Alkenylsilylation ${ }^{a}$

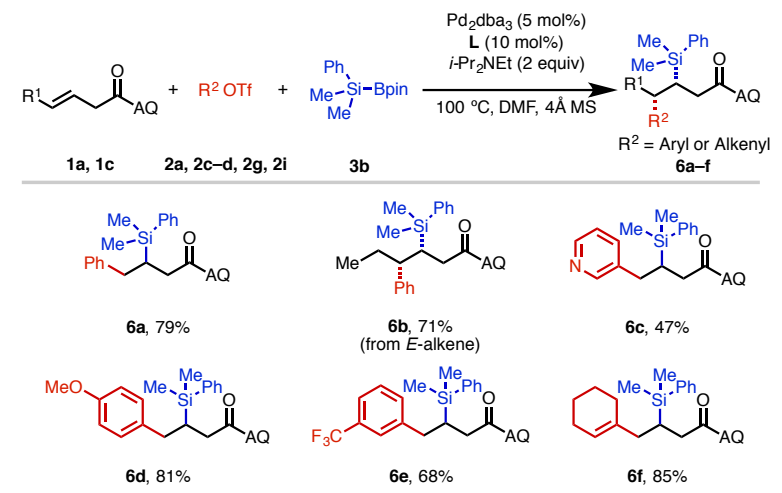

${ }^{a}$ Reaction conditions: 1a, $\mathbf{1 c}(0.1 \mathrm{mmol}), \mathbf{2 a}, \mathbf{2 c}-\mathbf{d}, \mathbf{2 g}, \mathbf{2 i}$ (1.5 equiv), $3 \mathbf{b}$ ( 3 equiv), $\mathrm{Pd}_{2} \mathrm{dba}_{3}(5 \mathrm{~mol} \%), \mathbf{L}$ ( $\left.10 \mathrm{~mol} \%\right), i-\operatorname{Pr}_{2} \mathrm{NEt}$ ( 2 equiv), $4 \AA$ MS (30 mg), $100{ }^{\circ} \mathrm{C}, \mathrm{N}_{2}, 38-44 \mathrm{~h}$. All the yields refer to the isolated yields.

To illustrate the synthetic utility of this family of 1,2-difunctionalized products, we performed a series of transformations on representative 1,2-carboborated products (Scheme 4). First, we carried out a 2-step transamination sequence to remove the AQ directing group, following Verho's procedure. ${ }^{21}$ Compounds $\mathbf{4 c}, \mathbf{4 j}$, and $\mathbf{4 l}$ were successfully transformed to the corresponding pyrrolidine amides in excellent yields. In addition, with $\mathrm{Ni}(\mathrm{tmhd})_{2}$ as a 
mediator, methanolysis of $\mathbf{4 c}$ was achieved in $78 \%$ yield. ${ }^{22}$ Finally, the boronate group of $\mathbf{8 c}$ was transformed to a vinyl and fluoro group, respectively (10 and $\mathbf{1 1}$ ), using literature methods. ${ }^{23,24}$

\section{Scheme 4. Diversification of Arylborylated Products}
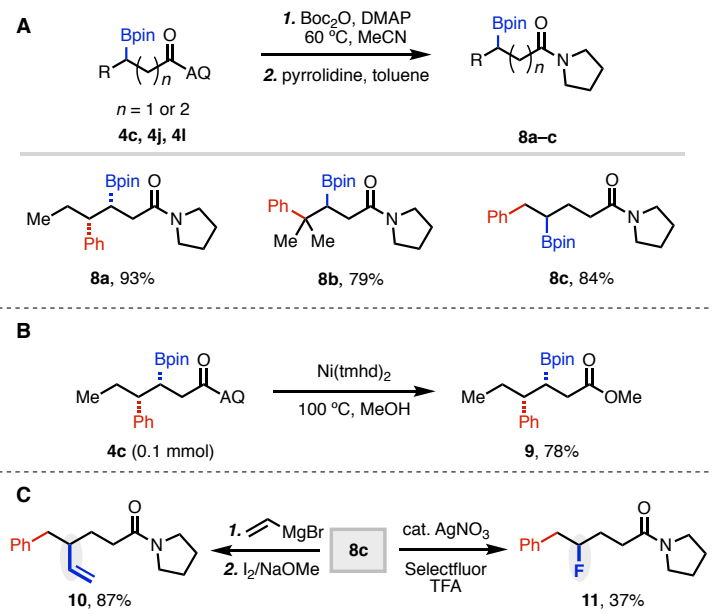

To conclude this study, we aimed to demonstrate the viability of establishing the absolute configuration of the newly installed stereocenters through use of a chiral bidentate directing group to facilitate the migratory insertion step. ${ }^{25,26}$ After some experimentation, we eventually identified 1-(pyridin-2-yl)ethan-1-amine (as shown in substrate 1y, Scheme 5), ${ }^{27}$ which is commercially available in enantiopure form, as a suitable chiral directing group. Under modified conditions using increased catalyst and ligand loading, 1,2-arylboration proceeded smoothly, forming product 7 in good yield with 9:1 $d r$ and no epimerization of the chiral auxiliary. Based on an X-ray crystal structure of the racemic form of product 7 , we were able to assign the relative stereochemistry of the major diastereomer. In our proposed stereoinduction model, the bottom methyl group is believed to affect the preferred coordination mode of the alkene to the palladium center during the migratory insertion step.

Scheme 5. Diastereoselective Arylboration Using a Removable Chiral Directing Group

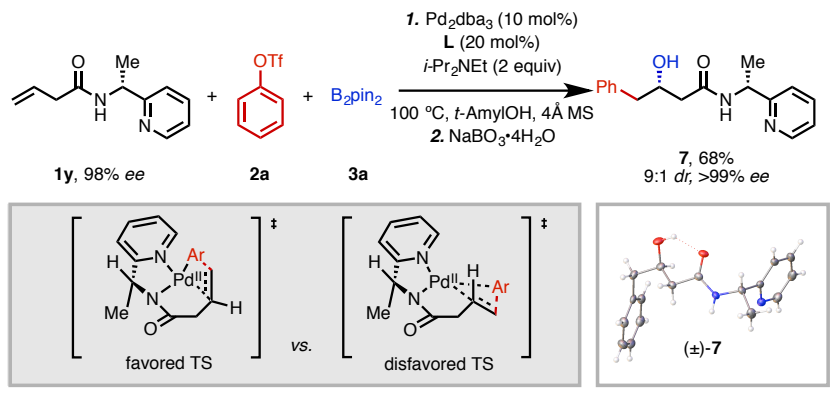

In conclusion, we have developed highly regio- and diastereoselective carboboration and carbosilylation reactions of alkenyl carbonyl compounds using a substrate directivity strategy. Compatible substrates include alkenes with various substitution patterns and benzo-fused heteroaromatics that react through five- and six-membered palladacycle intermediates. These methods allow direct access to carbonyl products containing boron and silicon groups at the $\beta$ and $\gamma$ positions. Furthermore, an array of aryl and alkenyl triflates are suitable carbon electrophiles. The reactions are scalable and operationally simple. Diversification of arylborylated products was also demonstrated, showcasing the synthetic versatility of the products. Finally, an example of diastereoselective 1,2-arylboration using a chiral directing group was shown.

\section{ASSOCIATED CONTENT}

\section{Supporting Information}

Experiment details, spectra data, copies of ${ }^{1} \mathrm{H},{ }^{19} \mathrm{~F}$ and ${ }^{13} \mathrm{C}$ NMR spectra, and X-ray crystallographic data. These materials are available free of charge via the Internet at http://pubs.acs.org.

\section{AUTHOR INFORMATION}

\section{Corresponding Author}

*E-mail: keary@scripps.edu

\section{Notes}

The authors declare no competing financial interest.

\section{ACKNOWLEDGMENT}

This work was financially supported by Scripps Research, Bristol-Myers Squibb (Unrestricted Grant), and the National Institutes of Health (5R35GM125052-02). Additionally, we gratefully acknowledge Bristol-Myers Squibb for a Graduate Fellowship (Z.L.), the A. P. Sloan Foundation and Dreyfus Foundation for young faculty fellowships (K.M.E.), and Nankai University College of Chemistry for an International Research Schlorship (X. L.). We thank Joseph Derosa, Xin Wang and Mingyu Liu for donation of alkene substrates. Dr. Jason Chen and Brittany Sanchez (Scripps Research Automated Synthesis Facility) are acknowledged for SFC and HRMS analysis. We further thank Dr. Milan Gembicky and Jake B. Bailey (UCSD) for X-ray crystallographic analysis.

\section{REFERENCES}

(1) For reviews, see: (a) Suginome, M. Catalytic Carboborations. Chem. Rec. 2010, 10, 348. (b) Liu, Z.; Gao, Y.; Zeng, T.; Engle, K. M. Transition-Metal-Catalyzed 1,2-Carboboration: Strategies, Mechanisms, and Stereocontrol. ChemRxiv 2019, DOI: 10.26434/chemrxiv.8859179.

(2) For examples of copper-catalyzed intermolecular 1,2-carboboration, see: (a) Yoshida, H.; Kageyuki, I.; Takaki, K. Copper-Catalyzed Three-Component Carboboration of Alkynes and Alkenes. Org. Lett. 2013, 15, 952. (b) Meng, F.; Haeffner, F.; Hoveyda, A. H. Diastereo- and Enantioselective Reactions of Bis(pinacolato)diboron, 1,3-Enynes, and Aldehydes Catalyzed by an Easily Accessible Bisphosphine-Cu Complex. J. Am. Chem. Soc. 2014, 136, 11304. (c) Su, W.; Gong, T.-J.; Lu, X.; Xu, M.-Y.; Yu, C.-G.; Xu, Z.-Y.; Yu, H.-Z.; Xiao, B.; Fu, Y. Ligand-Controlled Regiodivergent Copper-Catalyzed Alkylboration of Alkenes. Angew. Chem. Int. Ed. 2015, 54, 12957. (d) Parra, A.; López, A.; Díaz-Tendero, S.; Amenós, L.; Ruano, J. L. G.; Tortosa, M. Insight into the Copper-Catalyzed Borylation of Strained Alkenes. Synlett 2015, 26, 494. (e) Huang, Y.; Smith, K. B.; Brown, M. K. Copper-Catalyzed Borylacylation of Activated Alkenes with Acid Chlorides. Angew. Chem. Int. Ed. 2017, 56, 13314. (f) Kim, N.; Han, J. T.; Ryu, D. H.; Yun, J. Copper-Catalyzed Asymmetric Borylallylation of Vinyl Arenes. Org. Lett. 2017, 19, 6144.

(3) For examples of palladium-catalyzed intermolecular 1,2-carboboration, see: (a) Yang, K.; Song, Q. Pd-Catalyzed Regioselective Arylboration of Vinylarenes. Org. Lett. 2016, 18, 5460. (b) Yang, K.; Song, Q. Palladium-Catalyzed Arylboration of Bicyclic Alkenes. J. Org. Chem. 2016, 81, 1000. (c) Liu, Z.; Ni, H.-Q.; Zeng, T.; Engle, K. M. Catalytic Carboand Aminoboration of Alkenyl Carbonyl Compounds via Five- and Six-Membered Palladacycles. J. Am. Chem. Soc. 2018, 140, 3223. (d) Liu, Z.; Li, X.; Zeng, T.; Engle, K. M. Directed, Palladium(II)-Catalyzed Enantioselective anti-Carboboration of Alkenyl Carbonyl Compounds. ACS Catal. 2019, 9, 3260. (e) Bai, Z.; Zheng, S.; Bai, Z.; Song, F.; Wang, H.; 
Peng, Q.; Chen, G.; He, G. Palladium-Catalyzed Amide-Directed Enantioselective Carboboration of Unactivated Alkenes Using a Chiral Monodentate Oxazoline Ligand. ACS Catal. 2019, 9, 6502.

(4) For examples of nickel-catalyzed intermolecular alkene 1,2-carboboration, see: (a) Logan, K. M.; Sardini, S. R.; White, S. D.; Brown, M. K. Nickel-Catalyzed Stereoselective Arylboration of Unactivated Alkenes. J. Am. Chem. Soc. 2018, 140, 159. (b) Sardini, S. R.; Lambright, A. L.; Trammel, G. L.; Omer, H. M.; Liu, P.; Brown, M. K. Ni-Catalyzed Arylboration of Unactivated Alkenes: Scope and Mechanistic Studies. J. Am. Chem. Soc. 2019, 141, 9391. (c) Wang, W.; Ding, C.; Pang, H.; Yin, G. Nickel-Catalyzed 1,2-Arylboration of Vinylarenes. Org. Lett. 2019, 21, 3968. (d) Chen, L.-A.; Lear, A. R.; Gao, P.; Brown, M. K. Nickel-Catalyzed Arylboration of Alkenylarenes: Synthesis of Boron-Substituted Quaternary Carbons and Regiodivergent Reactions. Angew. Chem. Int. Ed. 2019, DOI: 10.1002/anie.201904861.

(5) For 1,2-carboboration using cooperative catalysis, see: (a) Semba, K.; Nakao, Y. Arylboration of Alkenes by Cooperative Palladium/Copper Catalysis. J. Am. Chem. Soc. 2014, 136, 7567. (b) Smith, K. B.; Logan, K. M.; You, W.; Brown, M. K. Alkene Carboboration Enabled by Synergistic Catalysis. Chem. Eur. J. 2014, 20, 12032. (c) Jia, T.; Cao, P.; Wang, B.; Lou, Y.; Yin, X.; Wang, M.; Liao, J. A Cu/Pd Cooperative Catalysis for Enantioselective Allylboration of Alkenes. J. Am. Chem. Soc. 2015, 137, 13760. (d) Semba, K.; Ohtagaki, Y.; Nakao, Y. Arylboration of 1-Arylalkenes by Cooperative Nickel/Copper Catalysis. Org. Lett. 2016, 18 3956.

(6) Xu, H.; White, P. B.; Hu, C.; Diao, T. Structure and Isotope Effects of the $\beta$-H Agostic ( $\alpha$-Diimine)Nickel Cation as a Polymerization Intermediate. Angew. Chem. Int. Ed. 2017, 56, 1535.

(7) For an example of $\mathrm{Ni}(\mathrm{II})$-catalyzed chain-walking arylboration, see: (a) Wang, W.; Ding, C.; Li, Y.; Li, Z.; Li, Y.; Peng, L.; Yin, G. Migratory Arylboration of Unactivated Alkenes Enabled by Nickel Catalysis. Angew. Chem. Ind. Ed. 2019, 58, 4612. For an example of $\mathrm{Pd}(0)$-catalyzed 1,1-arylboration, see: (b) Nelson, H. M.; Williams, B. D.; Miró, J.; Toste, F. D. Enantioselective 1,1-Arylborylation of Alkenes: Merging Chiral Anion Phase Transfer with Pd Catalysis. J. Am. Chem. Soc. 2015, 137, 3213.

(8) Huffman, T. R.; Wu, Y.; Emmerich, A.; Shenvi, R. A. Intermolecular Heck Coupling with Hindered Alkenes Directed by Potassium Carboxylates. Angew. Chem. Ind. Ed. 2019, 58, 2371.

(9) (a) Gurak, J. A., Jr.; Yang, K. S.; Liu, Z.; Engle, K. M. Directed, Regiocontrolled Hydroamination of Unactivated Alkenes via Protodepalladation. J. Am. Chem. Soc. 2016, 138, 5805. (b) Liu, Z.; Zeng, T.; Yang, K. S.; Engle, K. M. $\beta, \gamma$-Vicinal Dicarbofunctionalization of Alkenyl Carbonyl Compounds via Directed Nucleopalladation. J. Am. Chem. Soc. 2016, 138, 15122. (c) Liu, Z.; Wang, Y.; Wang, Z.; Zeng, T.; Liu, P.; Engle, K. M. Catalytic Intermolecular Carboamination of Unactivated Alkenes via Directed Aminopalladation. J. Am. Chem. Soc. 2017, 139, 11261. (d) Derosa, J.; Tran, V. T.; Boulous, M. N.; Chen, J. S.; Engle, K. M. Nickel-Catalyzed $\beta, \gamma$-Dicarbofunctionalization of Alkenyl Carbonyl Compounds via Conjunctive Cross-Coupling. J. Am. Chem. Soc. 2017, 139, 10657. (e) Zeng, T.; Liu, Z.; Schmidt, M. A.; Eastgate, M. D.; Engle, K. M. Directed, Palladium(II)-Catalyzed Intermolecular Aminohydroxylation of Alkenes Using a Mild Oxidation System. Org. Lett. 2018, 20, 3853. (f) Matsuura, R.; Jankins, T. C.; Hill, D. E.; Yang, K. S.; Gallego, G. M.; Yang, S.; He, M.; Wang, F.; Marsters, R. P.; McAlpine, I.; Engle, K. M. Palladium(II)-catalyzed $\gamma$-selective hydroarylation of alkenyl carbonyl compounds with arylboronic acids. Chem. Sci. 2018, 9, 8363.

(10) For selected examples, see: (a) Wang, H.; Bai, Z.; Jiao, T.; Deng, Z.; Tong, H.; He, G.; Peng, Q.; Chen, G. Palladium-Catalyzed Amide-Directed Enantioselective Hydrocarbofunctionalization of Unactivated Alkenes Using a Chiral Monodentate Oxazoline Ligand. J. Am. Chem. Soc. 2018, 140, 3542. (b) Wang, C.; Xiao, G.; Guo, T.; Ding, Y.; Wu, X.; Loh, T.-P. Palladium-Catalyzed Regiocontrollable Reductive Heck Reaction of Unactivated Aliphatic Alkenes. J. Am. Chem. Soc. 2018, 140, 9332. (c) Lv, H.; Xiao, L.-J.; Zhao, D.; Zhou, Q.-L. Ni(0)-catalyzed linear-selective hydroarylation of unactivated alkenes and styrenes with aryl boronic acids. Chem. Sci. 2018, 9, 6839. (d) Shen, H.-C.; Zhang, L.; Chen,
S.-S.; Feng, J.; Zhang, B.-W.; Zhang, Y.; Zhang, X.; Wu, Y.-D.; Gong, L.-Z. Enantioselective Addition of Cyclic Ketones to Unactivated Alkenes Enabled by Amine/Pd(II) Cooperative Catalysis. ACS Catal. 2019, 9, 791. (e) Zhang, Y.; Chen, G.; Zhao, D. Three-Component Vicinal-Diarylation of Alkenes via Transmetalation of Arylboronic Acids. Chem. Sci. 2019, DOI: 10.1039/C9SC02182E.

(11) For a representative review, see: Daugulis, O.; Roane, J.; Tran, L. D. Bidentate, Monoanionic Auxiliary-Directed Functionalization of Carbon-Hydrogen Bonds. Acc. Chem. Res. 2015, 48, 1053.

(12) Suginome, M.; Matsuda, T.; Ito, Y. Palladium- and Platinum-Catalyzed Silaboration of Methylenecyclopropanes through Selective Proximal or Distal C-C Bond Cleavage. J. Am. Chem. Soc. 2000, 122,11015 .

(13) Martin, R.; Buchwald, S. L. Palladium-Catalyzed Suzuki-Miyaura Cross-Coupling Reactions Employing Dialkylbiaryl Phosphine Ligands. Acc. Chem. Res. 2008, 41, 1461.

(14) Singh, R.; Vince, R. 2-Azabicyclo[2.2.1]hept-5-en-3-one: Chemical Profile of a Versatile Synthetic Building Block and its Impact on the Development of Therapeutics. Chem. Rev. 2012, 112, 4642.

(15) (a) Dong, J.; Krasnova, L.; Finn, M. G.; Sharpless, K. B. Sulfur(VI) Fluoride Exchange ( $\mathrm{SuFEx}$ ): Another Good Reaction for Click Chemistry. Angew. Chem. Int. Ed. 2014, 53, 9430. (b) Liang, Q.; Xing, P.; Huang, Z.; Dong, J.; Sharpless, K. B.; Li, X.; Jiang, B. Palladium-Catalyzed, Ligand-Free Suzuki Reaction in Water Using Aryl Fluorosulfates. Org. Lett. 2015, 17, 1942.

(16) Wertjes, W. C.; Southgate, E. H.; Sarlah, D. Recent Advances in Chemical Dearomatization of Nonactivated Arenes. Chem. Soc. Rev. 2018 47, 7996.

(17) Shen, C.; Zeidan, N.; Wu, Q.; Breuers, C. B. J.; Liu, R.-R.; Jia, Y.-X.; Lautens, M. Pd-Catalyzed Dearomative Arylborylation of Indoles. Chem. Sci. 2019, 10, 3118

(18) For examples of palladium-catalyzed carbosilylation of different $\pi$-systems, see: (a) Obora, Y.; Tsuji, Y.; Kawamura, T. 1,4-Carbosilyation of 1,3-Dienes via Palladium Catalyzed Three-Component Coupling Reaction. J. Am. Chem. Soc. 1995, 117, 9814. (b) Wu, M.-Y.; Yang, F.-Y.; Cheng, C.-H. Carbosilylation of Allenes Catalyzed by Palladium Complexes: A New Efficient Route to Substituted Allylic Silanes. J. Org. Chem. 1999, 64, 2471. (c) Hande, S. M.; Nakajima, M.; Kamisaki, H.; Tsukano, C.; Takemoto, Y. Flexible Strategy for Syntheses of Spirooxindoles using Palladium-Catalyzed Carbosilylation and Sakuri-Type Cyclization. Org. Lett. 2011, 13, 1828. (d) Shintani, R.; Kurata, H.; Nozaki, K. Intermolecular Three-Component Arylsilylation of Alkynes under Palladium/Copper Cooperative Catalysis. J. Org. Chem. 2016, 81, 3065.

(19) For selected examples of conceptually distinct approaches to catalytic alkene 1,2-carbosilylation, see: (a) Nii, S.; Terao, J.; Kambe, N Titanocene-Catalyzed Carbosilylation of Alkenes and Dienes Using Alkyl Halides and Chlorosilanes. J. Org. Chem. 2000, 65, 5291. (b) Liepins, V.; Bäckvall, J.-E. Silylcupration of styrenes followed by electrophilic trapping reaction. Chem. Commun. 2001, 265. (c) Nakamura, S.; Uchiyama, M. Regio- and Chemoselective Silylmetalation of Functionalized Terminal Alkenes. J. Am. Chem. Soc. 2007, 129, 28. (d) Yang, Y.; Song, R.-J.; Ouyang, X.-H.; Wang, C.-Y.; Li, J.-H.; Luo, S. Iron-Catalyzed Intermolecular 1,2-Difunctionalization of Styrenes and Conjugated Alkenes with Silanes and Nucleophiles. Angew. Chem. Int. Ed. 2017, 56, 7916.

(20) For selected examples of Pd-catalyzed $\mathrm{C}\left(\mathrm{sp}^{3}\right)-\mathrm{H}$ silylation enabled by bidentate directing groups, see: (a) Kanyiva, K. S.; Kuninobu, Y.; Kanai, M. Palladium-Catalyzed Direct $\mathrm{C}-\mathrm{H}$ Silylation and Germanylation of Benzamides and Carboxamides. Org. Lett. 2014, 16, 1968. (b) Liu, Y.-J.; Liu, Y.-H.; Zhang, Z.-Z.; Yan, S.-Y.; Chen, K.; Shi, B.-F. Divergent and Stereoselective Synthesis of $\beta$-Silyl- $\alpha$-Amino Acids through Palladium-Catalyzed Intermolecular Silylation of Unactivated Primary and Secondary C-H Bonds. Angew. Chem. Int. Ed. 2016, 55, 13859. (c) Deb, A.; Singh, S.; Seth, K.; Pimparkar, S.; Bhaskararao, B.; Guin, S.; Sunoj, R. B.; Maiti, D. Experimental and Computational Studies on Remote $\gamma-\mathrm{C}\left(\mathrm{sp}^{3}\right)-\mathrm{H}$ Silylation and Germanylation of Aliphatic Carboxamides. ACS 
Catal. 2017, 7, 8171. (d) Zhan, B.-B.; Fan, J.; Jin, L.; Shi, B.-F. Divergent Synthesis of Silicon-Containing Peptides via Pd-Catalyzed Post-Assembly $\gamma$-C $\left(\mathrm{sp}^{3}\right)-\mathrm{H}$ Silylation. ACS Catal. 2019, 9, 3298.

(21) Verho, O.; Lati, M. P.; Oshmann, M. A Two-Step Procedure for the Overall Transamidation of 8-Aminoquinoline Amides Proceeding via the Intermediate N-Acyl-Boc-Carbamates. J. Org. Chem. 2018, 83, 4464.

(22) Deguchi, T.; Xin, H.-L.; Morimoto, H.; Ohshima, T. Direct Catalytic Alcoholysis of Unactivated 8-Aminoquinoline Amides. ACS Catal. 2017, 7, 3157.

(23) (a) Sonawane, R. P.; Jheengut, V.; Rabalakos, C.; Larouche-Gauthier, R.; Scott, H. K.; Aggarwal, V. K. Enantioselective Construction of Quaternary Stereogenic Centers from Tertiary Boronic Esters: Methodology and Applications. Angew. Chem. Int. Ed. 2011, 50, 3760. (b) Hoang, G. L.; Takacs, J. M. Enantioselective $\gamma$-Borylation of Unsaturated Amides and Stereoretentive Suzuki-Miyaura Cross-Coupling. Chem. Sci. 2017, 8, 4511 .

(24) Li, Z.; Wang, Z.; Zhu, L.; Tan, X.; Li, C. Silver-Catalyzed Radical Fluorination of Alkylboronates in Aqueous Solution. J. Am. Chem. Soc

2014, 136, 16439 .
(25) For related examples of Heck-type processes employing chiral directing groups, see: (a) Buezo, N. D.; Mancheño, O. G.; Carretero, J. C. The 2-(N,N-Dimethylamino)phenylsulfinyl Group as an Efficient Chiral Auxiliary in Intramolecular Heck Reactions. Org. Lett. 2000, 2, 1451. (b) Nilsson, P.; Larhed, M.; Hallberg, A. A New Highly Asymmetric Chelation-Controlled Heck Arylation. J. Am. Chem. Soc. 2003, 125, 3430. For a review, see: (c) Oestreich, M. Neighbouring-Group Effects in Heck Reactions. Eur. J. Org. Chem. 2005, 783.

(26) For use of a chiral monodentate directing group in $\mathrm{Pd}(\mathrm{II})$-catalyzed alkene dioxygenation, see: Neufeldt, S. R.; Sanford, M. S. Asymmetric Chiral Ligand-Directed Alkene Dioxygenation. Org. Lett. 2013, 15, 46.

(27) Kim, Y.; Kim, S.-T.; Kang, D.; Sohn, T.-i.; Jang, E.; Baik, M.-H.; Hong, S. Stereoselective Construction of Sterically Hindered Oxaspirocycles via Chiral Bidentate Directing Group-Mediated $\mathrm{C}\left(\mathrm{sp}^{3}\right)-\mathrm{O}$ Bond Formation. Chem. Sci. 2018, 9, 1473.

\section{TOC Image}

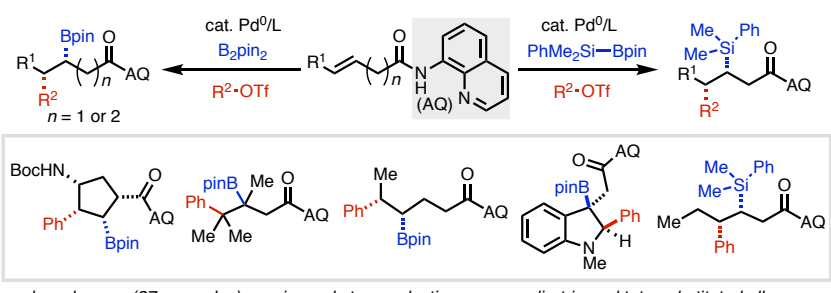

- broad scope (37 examples) • regio- and stereoselective • mono-, di-, tri-, and tetrasubstituted alkenes - conjugated and non-conjugated alkenes $\cdot$ dearomative difunctionalization 